\title{
POTENSI TENGKAWANG DI KEBUN MASYARAKAT DUSUN TEM'BAK, SINTANG, KALIMANTAN BARAT
}

\section{Potency of Tengkawang in Community Garden of Tem'bak Hamlet, Sintang, West Kalimantan}

\section{Supartini \& Muhammad Fajri}

Balai Besar Penelitian Dipterokarpa

Jl. AW. Syahrani No.68, Samarinda, Kalimantan Timur, Indonesia e-mail: tini_b2pd@yahoo.com, fajririmbawan@gmail.com

Diterima 11-01-2015, direvisi 22-06-2015, disetujui 06-07-2015

\begin{abstract}
ABSTRAK
Penelitian ini bertujuan untuk mengetahui potensi tengkawang di kebun masyarakat sehingga pengelolaan tengkawang dapat dilakukan secara lestari. Pengukuran potensi tengkawang dilakukan dengan pembuatan plot seluas 2,16 ha atau 54 plot pada 3 topograf yaitu di lembah 27 plot, lereng 14 plot dan bukit 13 plot di Dusun Tem’bak, Desa Gurung Mali, Kecamatan Tempunak, Kabupaten Sintang, Kalimantan Barat. Hasil penelitian menunjukkan bahwa tengkawang yang terdapat di kebun masyarakat berjumlah 93 pohon atau memiliki kerapatan 43,06 pohon/ha dan jenis yang ditemukan yaitu Shorea macrophylla, S. stenoptera dan S. beccariana. Rataan potensi luas bidang dasar dan volume kayu ketiga jenis tengkawang yaitu 0,29 $\mathrm{m} 2$ dan 2,67 m3. Pohon tengkawang di lembah memiliki luas bidang dasar dan volume kayu yang lebih besar dibandingkan dengan pohon tengkawang di lereng dan bukit. Potensi S. stenoptera dari luas bidang dasar berbeda nyata dengan S. macrophylla dan S. beccariana, sedangkan potensi volume kayu ketiga jenis ini tidak berbeda nyata. Kelima kelas diameter tegakan tengkawang memiliki luas bidang dasar dan volume kayu yang berbeda nyata. S. macrophylla ditemukan di lembah, lereng dan bukit. S. stenoptera terdapat di lembah dan lereng. S. beccariana ditemukan hanya di bukit. Potensi tegakan tengkawang di kebun masyarakat masih tinggi untuk dikelola secara lestari.
\end{abstract}

Kata kunci: Tengkawang, potensi tegakan, sebaran

\section{ABSTRACT}

The aims of this study was determined potency of Tengkawang in community gardens so that it can be managed sustainably. Tengkawang potential assesment had done by making the plot area of 2,16 ha or 54 plots in 3 topography namely at valley 27 plot, hillside 14 plot and hill 13 plot in Tem'bak Hamlet, Gurung Mali village, Tempunak Sub district, Sintang, West Kalimantan. The result showed that community gardens contained 93 trees or it has density of 43,06 tree/ ha consist of Shorea macrophylla, S. stenoptera and S. beccariana. Mean potential of basal area and timber volume were $0.29 \mathrm{~m} 2$ and $2.67 \mathrm{~m} 3$. Basal area and timber volume of tengkawang trees in the valley had greater than tengkawang trees in hillside and hill. Basal area of S. stenoptera was signif cantly different than S. macrophylla and S. beccariana, while timber volume of third spesies were not signif cantly different. The ffth of tengkawang diameter class had basal area and timber volume signif cantly different. S. macrophylla was found in valley, hillside and hill. S. stenoptera was found in valley and hillside. S. beccariana was found only in the hill. Standing stock of tengkawang in community garden still high for sustainable utilization.

Keywords: Tengkawang, standing stock, distribution

\section{PENDAHULUAN}

Masyarakat dusun Tem’bak memiliki mata pencaharian diantaranya berkebun. Kebun yang mereka miliki dikelola dengan teknikteknik tertentu sesuai dengan kearifan lokal dan mengikuti aturan-aturan sosial sehingga membentuk keanekaragaman yang kompleks menyerupai ekosistem hutan alam. Teknik-tehnik tertentu tersebut misalnya dengan menanam berbagai jenis pohon yang bisa dipanen dalam jangka pendek (seperti getah karet), jangka menengah atau musiman (seperti tanaman durian, nangka, rambutan, cempedak) dan jangka panjang (seperti tengkawang untuk kebutuhan kayu dan buahnya). Hal ini terkenal dengan istilah agroforestry tembawang. ITTO (2011) 
melaporkan bahwa tembawang merupakan ekosistem unik yang didalamnya tidak hanya nilai ekonomi, tapi juga nilai keanekaragaman hayati dan konservasi. Sedangkan aturan-aturan sosial yang ada adalah kesepakatan anggota masyarakat yang tertuang dalam hukum adat, misalnya boleh menebang pohon tengkawang hanya untuk kebutuhan membangun rumah saja bukan untuk dijual.

Kebun masyarakat di dusun tersebut masih terpelihara dengan baik karena memberi sumbangsih dari sumber airnya. Sumber air yang ada digunakan untuk Pembangkit Listrik Mikro Hidro (PLTMH). Desa Gurung Mali memiliki 4 unit PLTMH yaitu PLTMH Sungai Piling dengan anggota 7 KK, PLTMH Sinar Gembala Sawak dengan anggota $15 \mathrm{KK}$, PLTMH Sinar Tuja Tengguli dengan anggota 33 KK dan PLTMH Kaki Gurung dengan anggota 24 KK. Masyarakat sadar bila kebun ini tidak dipertahankan keberadaannya maka desa mereka akan gelap gulita. Tengkawang merupakan salah satu jenis yang relatif banyak dan masih terjaga keberadaannya di kebun masyarakat tersebut. Fajri et al. (2012) menyatakan bahwa potensi pohon tengkawang masih terjaga dengan baik di kebun masyarakat Kalimantan Barat karena masyarakat mempunyai kearifan lokal dalam mengelola pohon tengkawang yaitu dengan cara:

1. Buah tengkawang disemai di halaman belakang rumah mereka. Buah tengkawang tersebut ditanam di media polybag dan dibiarkan tumbuh sampai siap ditanam, setelah itu bibit ditanam kembali di area kebun mereka.

2. Pohon tengkawang tidak boleh ditebang kecuali untuk membangun rumah.

3. Adanya larangan untuk menjual kayu pohon tengkawang, bila ada yang melanggar maka akan mendapat hukuman adat.

Tengkawang telah lama dibudidaya oleh masyarakat karena bernilai ekonomi tinggi. Tengkawang memiliki potensi kayu dan non kayu. Tengkawang adalah nama daerah beberapa jenis Shorea, yang merupakan bagian dari family
Dipterokarpa. Dalam perdagangan, tengkawang termasuk dalam kelompok Meranti Merah.

Potensi tengkawang yang dimanfaatkan oleh masyarakat yaitu buah, batang dan damarnya. Riko et al. (2013) menyatakan bahwa pendapatan masyarakat di Kecamatan Embaloh Hilir, Kabupaten Kapuas Hulu, Kalimantan Barat dari hasil pemanfaatan tengkawang pada pemanenan tahun 2008 yaitu pendapatan ratarata dari pemanfaatan buah $\mathrm{Rp}$ 10.812.962,00/ KK/panen (dengan harga buah Rp 7.000,00/kg), batang Rp. 566.769,23/KK/panen (dengan harga kayu Rp 1.340.000,00/ $\mathrm{m}^{3}$ ) dan damar atau getah Rp 4.700,00/KK/panen (dengan harga damar Rp $1.000,00 / \mathrm{kg})$.

Inventarisasi potensi keberadaan pohon tengkawang perlu dilakukan untuk mendukung pemanfaatan tengkawang secara optimal di kebun masyarakat. Penelitian ini bertujuan untuk mengetahui potensi tengkawang di kebun masyarakat dusun Tem'bak sehingga pengelolaan tengkawang dapat dilakukan secara lestari.

\section{METODOLOGI PENELITIAN}

Penelitian dilakukan di area kebun masyarakat Dusun Tem'bak, Desa Gurung Mali, Kecamatan Tempunak, Kabupaten Sintang, Kalimantan Barat (Gambar 1.). Luas wilayah Desa Gurung Mali 8000 ha. Desa tersebut memiliki hutan yang masih dilestarikan oleh masyarakat yaitu hutan Ribang Ayau dengan luas wilayah 55 ha yang akan dijadikan penangkaran Orang Utan, hutan Jalan Ramut dengan luas 15 ha, hutan Gupung Kabit dengan luas 10 ha dan hutan Sengkuang dengan luas 7 ha. Kebun masyarakat berada dalam hutan tersebut.

Pengukuran potensi tengkawang dilakukan dengan pembuatan plot seluas 2,16 ha atau 54 plot dengan masing-masing plot berukuran $20 \mathrm{~m}$ x $20 \mathrm{~m}$ pada topograf lembah (27 plot), lereng (14 plot) dan bukit (13 plot). Jumlah plot pada beberapa topograf ini berbeda disesuaikan dengan potensi tengkawang pada tiap topograf . Dari pengamatan yang dilakukan, pohon-pohon tengkawang di lembah relatif lebih banyak dibandingkan dengan di lereng dan bukit. 
Penentuan lokasi penelitian dilakukan secara purposif sampling yaitu lokasi yang terpilih didalamnya terdapat potensi pohon tengkawang. Untuk mewakili kondisi lapangan maka sampel dipilih pada topograf lembah, lereng dan bukit. Tanaman yang diinventarisir adalah tanaman pada tingkat tiang (diameter $10-20 \mathrm{~cm}$ ) dan pohon (diameter $>20 \mathrm{~cm}$ ). Kegiatan yang dilakukan meliputi pengukuran pohon (diameter dan tinggi bebas cabang) dan pengamatan jumlah pohon tengkawang.

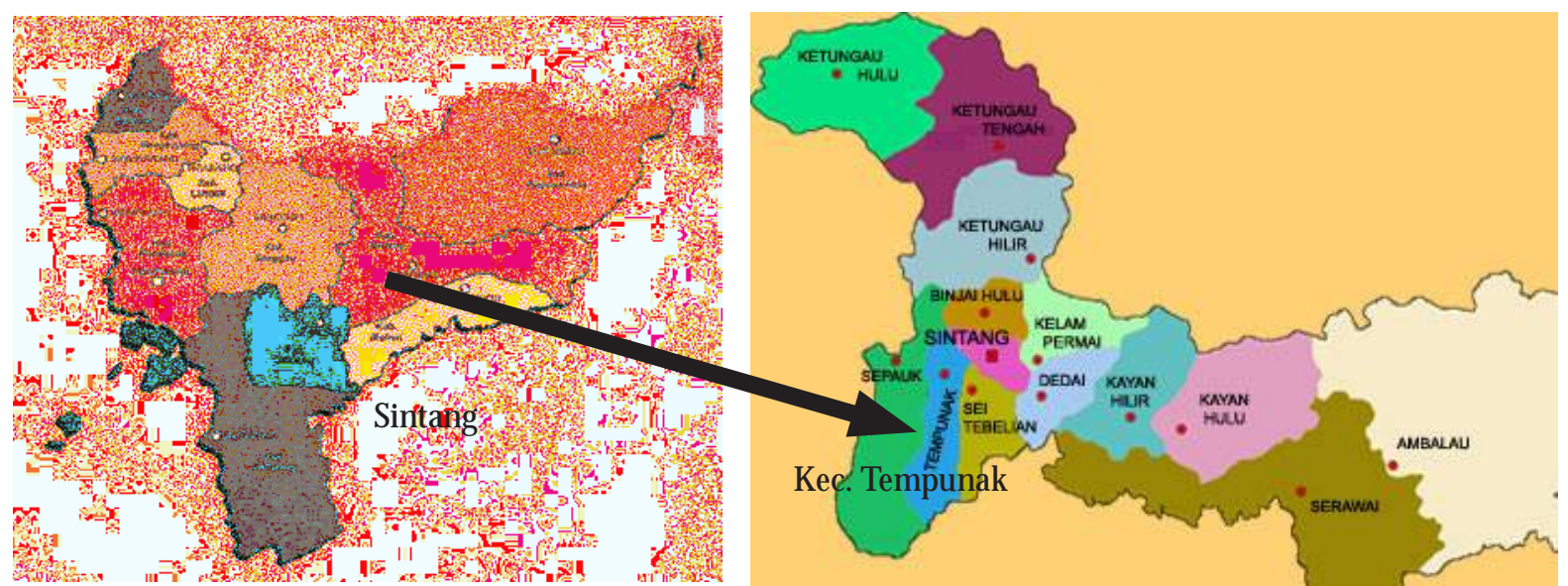

Gambar 1. (a). Lokasi Kabupaten Sintang di Kalimantan Barat; (b) Lokasi Kecamatan Tempunak di Kabupaten Sintang

Figure 1. (a) Sintang Regency location at West Kalimantan; (b) Tempunak Sub-District location at Sintang Regency

Sumber: Peta Kalbar dan Peta Sintang (n.d.)

Potensi tengkawang yang dibahas dalam tulisan ini yaitu khusus pada potensi tegakan dan sebarannya di kebun masyarakat. Potensi tegakan dilihat dari luas bidang dasar dan volume kayunya yang dikelompokkan berdasarkan topograf lembah, lereng dan bukit dari jenis $S$. macrophylla, S. stenoptera dan S. beccariana. Diameter dibedakan berdasarkan ukuran diameter $\leq 25 \mathrm{~cm}, 25,1-50 \mathrm{~cm}, 50,1-75 \mathrm{~cm}$, 75,1-100 cm dan $>100 \mathrm{~cm}$. Sedangkan sebaran tengkawang dilihat dari jumlah pohonnya, kemudian diklasif kasikan berdasarkan topograf dan kelas diameter.

Data dianalisa dengan menggunakan software SAS (Statistical Analysis System) untuk Windows versi 9.0 (Hardiyanto, 2008). Rumus-rumus yang digunakan dalam analisis data sebagai berikut:

Volume Kayu $=1 / 4$ Л. $(\mathrm{d} / 100)^{2}$. t.f

Luas Bidang Dasar $=1 / 4 Л .(\mathrm{d} / 100)^{2}$

Keterangan:

$\pi=$ Konstanta $(3,14)$

$\mathrm{d}=$ Diameter setinggi dada atau $20 \mathrm{~cm}$ di atas banir (cm)

$\mathrm{t} \quad=$ Tinggi batang bebas cabang $(\mathrm{m})$

$\mathrm{f} \quad=$ Faktor bentuk pohon $(0,6)$

\section{HASIL DAN PEMBAHASAN}

\section{A. Potensi Tegakan}

Tengkawang yang ditemukan di kebun masyarakat Dusun Tem’bak, Desa Gurung Mali, Kecamatan Tempunak, Kabupaten Sintang, Kalimantan Barat berjumlah 93 pohon/2,16 ha atau memiliki kerapatan 43,06 pohon/ha dan jenis yang ditemukan yaitu S. macrophylla 62 pohon, S. stenoptera 28 pohon dan S. beccariana 3 pohon. Pohon tengkawang dari ketiga jenis tersebut memiliki diameter berkisar antara 12 $152 \mathrm{~cm}$ dan tinggi bebas cabang 3,29 - 29,43 m dengan rata-rata diameter $52,73 \mathrm{~cm}$ dan tinggi bebas cabang 13,78 m. Kisaran diameter dan tinggi bebas cabang ketiga jenis tengkawang pada beberapa topograf disajikan pada Tabel 1 . Potensi tegakan berdasarkan topograf disajikan pada Tabel 2, jenis pada Tabel 3, kelas diameter pada Tabel 4 dan interaksi topograf, jenis dan kelas diameter pada Tabel 5. Rata-rata potensi tegakan tengkawang dari luas bidang dasar dan volume kayu adalah 0,29 $\mathrm{m}^{2}$ dan 2,67 $\mathrm{m}^{3}$.

Potensi tegakan tengkawang pada Tabel 2 menunjukkan bahwa di lembah berbeda nyata 
dengan lereng dan bukit. Pohon tengkawang di lembah memiliki luas bidang dasar dan volume kayu yang lebih besar dibandingkan dengan pohon tengkawang di lereng dan bukit. Hal ini kemungkinan diakibatkan oleh tanah di lembah lebih subur, sedangkan di lereng dan bukit tanahnya kurang subur akibat erosi yang terjadi secara alami. Purwaningsih (2006) menyatakan bahwa hutan atau pohon-pohon yang telah mengalami gangguan atau tumbuh pada kondisi ekstrem, cenderung memiliki luas bidang dasar lebih kecil karena banyaknya pohon berukuran kecil. Pohon berukuran kecil ini diduga disebabkan oleh pertumbuhan pohon yang lambat. Muhdi (2004) menyatakan bahwa pertumbuhan pohon yang lambat dikarenakan pembentukan sel baru yang berasal dari pembelahan sel sangat lambat dan lebih banyak terjadi proses penuaan sel. Penuaan sel ini membentuk kayu teras dalam pohon. Di dalam kayu teras, semua sel-sel penyusunnya adalah sel yang sudah mati dan tidak mengalami penambahan besarnya sel.

Tabel 1. Kisaran Diameter dan Tinggi Bebas Cabang Ketiga Jenis Tengkawang pada Beberapa Topograf Table 1. Range of Diameter and Clear-Bole of Three Spesies Tengkawang on Several Topography

\begin{tabular}{llll}
\hline Topograf (Topography) & Jenis (Species) & D $(\mathrm{cm})$ & Tbc $(\mathrm{m})$ \\
\hline Lembah & Shorea macrophylla & $16,6-132$ & $3,29-26,77$ \\
Lembah & Shorea stenoptera & $14,4-152$ & $3,53-31,69$ \\
Lereng & Shorea macrophylla & $12,4-70$ & $6,76-24,80$ \\
Lereng & Shorea stenoptera & $12-75$ & $7,07-25$ \\
Bukit & Shorea macrophylla & $24,2-55$ & $9,9-15,83$ \\
Bukit & Shorea beccariana & $40-70$ & $17-21$ \\
\hline Rataan & & 52,73 & 13,78 \\
\hline
\end{tabular}

Sumber: diolah dari data primer.

Tabel 2. Potensi Tegakan Tengkawang Berdasarkan Topograf

Table 2. Potency of Tengkawang Based on Topography

\begin{tabular}{lll}
\hline $\begin{array}{l}\text { Topograf } \\
\text { (Topography) }\end{array}$ & $\begin{array}{l}\text { Luas Bidang Dasar }\left(\mathrm{m}^{2}\right) \\
\text { (Basal Area) }\end{array}$ & $\begin{array}{l}\text { Volume Kayu }\left(\mathrm{m}^{3}\right) \\
\text { (Timber Volume) }\end{array}$ \\
\hline Lembah & $0,45 \mathrm{a}$ & $3,14 \mathrm{a}$ \\
Lereng & $0,15 \mathrm{~b}$ & $1,19 \mathrm{~b}$ \\
Bukit & $0,16 \mathrm{~b}$ & $1,32 \mathrm{~b}$ \\
\hline
\end{tabular}

Sumber: diolah dari data primer.

Keterangan: angka pada baris yang diikuti satu atau lebih huruf yang sama tidak berbeda nyata pada taraf 5\%.

Tabel 3. Potensi Tegakan Tengkawang Berdasarkan Jenis

Table 3. Potency of Tengkawang Based on Spesies

\begin{tabular}{lll}
\hline $\begin{array}{l}\text { Jenis } \\
\text { (Species) }\end{array}$ & $\begin{array}{l}\text { Luas Bidang Dasar }\left(\mathrm{m}^{2}\right) \\
\text { (Basal Area) }\end{array}$ & $\begin{array}{l}\text { Volume Kayu }\left(\mathrm{m}^{3}\right) \\
(\text { Timber Volume })\end{array}$ \\
\hline Shorea macrophylla & $0,25 \mathrm{~b}$ & $1,75 \mathrm{a}$ \\
Shorea stenoptera & $0,36 \mathrm{a}$ & $2,49 \mathrm{a}$ \\
Shorea beccariana & $0,26 \mathrm{~b}$ & $2,66 \mathrm{a}$ \\
\hline
\end{tabular}

Sumber: diolah dari data primer.

Keterangan: angka pada baris yang diikuti satu atau lebih huruf yang sama tidak berbeda nyata pada taraf 5\%.

Potensi tengkawang seluruhnya bila dibandingkan dengan habitatnya di lembah, lereng dan bukit maka S. macrophylla memiliki luas bidang dasar 18,43\%, 7,24\%, 1,14\% dari $58,11 \mathrm{~cm}^{2}$, dan volume kayu 20,37\%, 8,18\%, $1,05 \%)$ dari $462,68 \mathrm{~m}^{3}$, S. stenoptera memiliki luas bidang dasar 14,21\%, 3,32\%, 0\% dan volume kayu 18,62\%, 3,77\%, 0\% dan S. beccariana memiliki luas bidang dasar $0 \%, 0 \%, 1,32 \%$ dan volume kayu $0 \%, 0 \%, 1,77 \%$. Pada ketiga topograf , $S$. macrophylla mendominasi dalam hal luas bidang dasar dan volume kayu. 
Berdasarkan jenis, potensi tegakan tengkawang dari luas bidang dasar pada S. stenoptera berbeda nyata dengan $S$. macrophylla dan $S$. beccariana, sedangkan potensi tegakan tengkawang dari volume kayu, ketiga jenis ini tidak berbeda nyata (Tabel 3). S. stenoptera memiliki luas bidang dasar paling besar dari 2 jenis lainnya dikarenakan diameter pohon jenis ini, ada yang paling besar yaitu $152 \mathrm{~cm}$. Hal ini diduga disebabkan oleh kondisi lingkungan dan tempat tumbuh yang sesuai untuk jenis tersebut sehingga pertumbuhannya dapat maksimal. Jenis ini memperoleh unsur hara dan air yang cukup untuk perkembangan diameter dan tinggi pohon. Pohon-pohon tengkawang khususnya S. macrophylla dan S. stenoptera yang ada di kebun masyarakat ini sebagian besar tumbuh di sekitar sungai baik pada topografi lembah maupun lereng. Serupa dengan penelitian yang dilakukan Fajri et al. (2012) yang menyatakan bahwa S. macrophylla ditemukan menyebar secara acak dan merata di pinggir sungai atau daerah yang mempunyai karakter topograf landai dan datar. Sidiyasa et al. (2006) menyatakan bahwa tengkawang (S. macrophylla) termasuk jenis tumbuhan yang dijumpai di daerah tepi sungai, terutama di daerah datar hingga sedikit lereng. Wahyudi et al. (2010) menyatakan bahwa $S$. stenoptera sebagian besar tumbuh di daerah sekitar aliran sungai (daerah lembah) dan daerahdaerah dengan kelerengan kurang dari 25\% dengan drainase yang baik. Newman et al. (1999) menyatakan bahwa $S$. beccariana tumbuh pada lahan pamah dan perbukitan kering sampai 1350 m dpl.

Tabel 4 menunjukkan bahwa kelima kelas diameter dari tegakan tengkawang memiliki luas bidang dasar yang berbeda nyata. Besarnya luas bidang dasar dan volume kayu mengikuti diameter pohon yang berarti bahwa semakin besar diameter pohon maka luas bidang dasar dan volume kayunya juga semakin besar. Sebaliknya, pohon yang berdiameter kecil memiliki luas bidang dasar dan volume kayu yang juga rendah. Kondisi iklim mikro dan kondisi tanah di lembah diduga lebih baik daripada di daerah yang lebih tinggi atau di bukit dan punggung.

Tabel 4. Potensi Tegakan Tengkawang Berdasarkan Kelas Diameter

Table 4. Potency of Tengkawang Based on Diameter Class

\begin{tabular}{lll}
\hline $\begin{array}{l}\text { Kelas Diameter }(\mathrm{cm}) \\
(\text { Diameter Class })\end{array}$ & $\begin{array}{l}\text { Luas Bidang Dasar }\left(\mathrm{m}^{2}\right) \\
(\text { Basal Area })\end{array}$ & $\begin{array}{l}\text { Volume Kayu }\left(\mathrm{m}^{3}\right) \\
\text { (Timber Volume })\end{array}$ \\
\hline$\leq 25$ & $0,02 \mathrm{e}$ & $0,14 \mathrm{e}$ \\
$25,1-50$ & $0,12 \mathrm{~d}$ & $1,04 \mathrm{~d}$ \\
$50,1-75$ & $0,32 \mathrm{c}$ & $2,65 \mathrm{c}$ \\
$75,1-100$ & $0,65 \mathrm{~b}$ & $5,11 \mathrm{~b}$ \\
$>100$ & $1,32 \mathrm{a}$ & $12,6 \mathrm{a}$ \\
\hline
\end{tabular}

Sumber: diolah dari data primer

Keterangan : angka pada baris yang diikuti satu atau lebih huruf yang sama tidak berbeda nyata pada taraf 5\%

Potensi tegakan tengkawang dari interaksi topograf , jenis dan kelas diameter ini diperlukan untuk mengetahui potensi tegakan tengkawang pada masing-masing topograf, jenis dan kelas diameter. Tabel 5 menunjukkan bahwa luas bidang dasar terendah terdapat pada jenis $S$. stenoptera dengan kelas diameter $<25 \mathrm{~cm}$ di topograf lereng, sedangkan untuk luas bidang dasar tertinggi terdapat pada jenis yang sama dengan kelas diameter $>100 \mathrm{~cm}$ di topograf lembah. Untuk volume kayu terendah terdapat pada jenis S. macrophylla di topograf lembah dan S. stenoptera di topograf lereng yang masingmasing pada kelas diameter $<25 \mathrm{~cm}$ dan volume kayu tertinggi terdapat pada jenis $S$. stenoptera dengan kelas diameter $>100 \mathrm{~cm}$ di topograf lembah. Hal ini dikarenakan Pohon-pohon tengkawang yang berdiameter $>100 \mathrm{~cm}$ lebih mendominasi untuk ruang tumbuh dibandingkan dengan pohon-pohon yang berdiameter $>25 \mathrm{~cm}$ sehingga mendapatkan sinar matahari penuh dan unsur hara yang cukup untuk pertumbuhannya. 
Tabel 5. Potensi Tegakan Tengkawang dari Interaksi Topograf, Jenis dan Kelas Diameter Table 5. Potency of Tengkawang from Topography, Spesies and Diameter Class Interaction

\begin{tabular}{|c|c|c|c|c|}
\hline $\begin{array}{l}\text { Topograf } \\
\text { (Topography) }\end{array}$ & $\begin{array}{l}\text { Jenis } \\
\text { (Species) }\end{array}$ & $\begin{array}{l}\text { Kelas Diameter }(\mathrm{cm}) \\
\text { (Diameter Class) }\end{array}$ & $\begin{array}{l}\text { Luas Bidang Dasar }\left(\mathrm{m}^{2}\right) \\
\text { (Basal area) }\end{array}$ & $\begin{array}{l}\text { Volume Kayu }\left(\mathrm{m}^{3}\right) \\
(\text { Timber Volume) }\end{array}$ \\
\hline \multirow[t]{2}{*}{ Lembah } & Shorea macrophylla & $\begin{array}{l}\leq 25 \\
25,1-50 \\
50,1-75 \\
75,1-100 \\
>100\end{array}$ & $\begin{array}{l}0,02 \\
0,13 \\
0,35 \\
0,66 \\
1,17 \\
\end{array}$ & $\begin{array}{l}0,07 \\
0,86 \\
2,85 \\
5,13 \\
12,58 \\
\end{array}$ \\
\hline & Shorea stenoptera & $\begin{array}{l}\leq 25 \\
25,1-50 \\
50,1-75 \\
75,1-100 \\
>100\end{array}$ & $\begin{array}{l}0,03 \\
0,09 \\
0,32 \\
0,62 \\
1,43 \\
\end{array}$ & $\begin{array}{l}0,09 \\
1,00 \\
3,11 \\
5,14 \\
15,84 \\
\end{array}$ \\
\hline \multirow[t]{2}{*}{ Lereng } & Shorea macrophylla & $\begin{array}{l}\leq 25 \\
25,1-50 \\
50,1-75\end{array}$ & $\begin{array}{l}0,03 \\
0,14 \\
0,27\end{array}$ & $\begin{array}{l}0,17 \\
1,33 \\
2,24\end{array}$ \\
\hline & Shorea stenoptera & $\begin{array}{l}\leq 25 \\
25,1-50 \\
50,1-75\end{array}$ & $\begin{array}{l}0,01 \\
0,12 \\
0,35\end{array}$ & $\begin{array}{l}0,07 \\
1,05 \\
3,40\end{array}$ \\
\hline \multirow[t]{2}{*}{ Bukit } & Shorea macrophylla & $\begin{array}{l}\leq 25 \\
25,1-50 \\
50,1-75\end{array}$ & $\begin{array}{l}0,05 \\
0,09 \\
0,24\end{array}$ & $\begin{array}{l}0,34 \\
0,78 \\
1,41\end{array}$ \\
\hline & Shorea beccariana & $\begin{array}{l}25,1-50 \\
50,1-75\end{array}$ & $\begin{array}{l}0,13 \\
0,32\end{array}$ & $\begin{array}{l}1,58 \\
3,30\end{array}$ \\
\hline
\end{tabular}

Sumber : diolah dari data primer

\section{B. Sebaran Tengkawang}

Sebaran tengkawang pada beberapa topograf dapat dilihat pada Gambar 2 dan sebaran tengkawang berdasarkan kelas diameter disajikan pada Tabel 6. Sebaran tengkawang berdasarkan topograf yaitu S. macrophylla tersebar pada lembah, lereng dan bukit; S. stenoptera terdapat pada lembah dan lereng; dan S. beccariana ditemukan hanya di bukit. Dari 223 pohon yang diinventarisasi di lembah, S. macrophylla berjumlah 28 pohon $(12,56 \%)$ dan S. stenoptera berjumlah 14 pohon (6,28\%). Dari 206 pohon di lereng, S. macrophylla berjumlah 28 pohon (13,59\%) dan S. stenoptera berjumlah 14 pohon (6,79\%) dan dari 282 pohon di bukit, S. macrophylla berjumlah 6 pohon $(2,13 \%)$ dan $S$. beccariana berjumlah 3 pohon (1,06\%). Tengkawang yang dominan di lembah, lereng dan bukit di kebun masyarakat Dusun Tem’bak adalah jenis S. macrophylla.

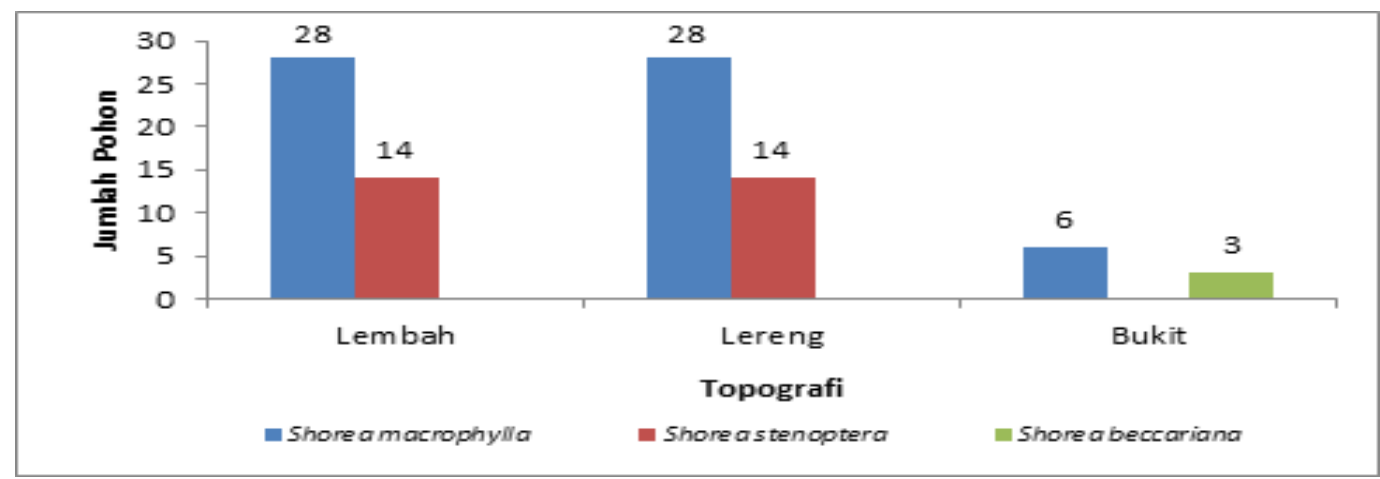

Gambar 2. Sebaran Tengkawang Berdasarkan pada Topograf Sumber: diolah dari data primer

Figure 2. Tengkawang Distribution Based on Topography 
Tabel 6. Sebaran Tengkawang Berdasarkan Kelas Diameter Table 6. Distribution of Tengkawang Based on Diameter Class

\begin{tabular}{|c|c|c|c|c|c|}
\hline \multirow[t]{2}{*}{$\begin{array}{l}\text { Jenis } \\
\text { (Species) }\end{array}$} & \multicolumn{5}{|c|}{$\begin{array}{l}\text { Kelas diameter }(\mathrm{cm}) \\
\text { (Diameter class) }\end{array}$} \\
\hline & $\leq 25$ & $25,1-50$ & $50,1-75$ & $75,1-100$ & $>100$ \\
\hline \multicolumn{6}{|c|}{ Shorea macrophylla } \\
\hline Lembah & 2 & 8 & 12 & 3 & 3 \\
\hline Lereng & 5 & 16 & 7 & - & - \\
\hline Bukit & 1 & 4 & 1 & - & - \\
\hline \multicolumn{6}{|c|}{ Shorea stenoptera } \\
\hline Lembah & 2 & 3 & 3 & 2 & 4 \\
\hline Lereng & 2 & 10 & 2 & - & - \\
\hline \multicolumn{6}{|c|}{ Shorea beccariana } \\
\hline Bukit & - & 1 & 2 & - & - \\
\hline Jumlah & 12 & 42 & 27 & 5 & 7 \\
\hline
\end{tabular}

Sumber : diolah dari data primer

Tabel 6 menunjukkan bahwa dari 710 pohon di kebun masyarakat, pohon tengkawang yang ada tersebar pada kelas diameter $\leq 25 \mathrm{~cm}$ sebanyak 1,69\%, kelas diameter 25,1-50 cm sebanyak 5,91\%, kelas diameter 50,1-75 cm sebanyak 3,80\%, kelas diameter 75,1-100 cm sebanyak $0,70 \%$ dan kelas diameter $>100 \mathrm{~cm}$ sebanyak 0,98\%. S. macrophylla, S. stenoptera dan $S$. beccariana pada kelas diameter $\leq 25 \mathrm{~cm}$ sebanyak 0,70\%, 0,28\% dan 0\%, kelas diameter 25,1-50 cm sebanyak 2,25\%, 1,41\% dan 0,14\%, kelas diameter 50,1-75 cm sebanyak 1,69\%, 0,42\% dan 0,28\%, kelas diameter 75,1-100 cm sebanyak 0,42\%, 0,28\% dan $0 \%$, dan kelas diameter $>100 \mathrm{~cm}$ sebanyak $0,42 \%, 0,56 \%$ dan $0 \%$. Pohon tengkawang banyak terdapat pada kelas diameter 25,1-50 cm dan terbanyak untuk jenis $S$. macrophylla di lereng.

Kondisi potensi pohon tengkawang di Dusun Tem'bak masih tergolong dalam kategori baik dan dapat dilakukan pemanfaatan hutan secara lestari. Hal ini terlihat dari jumlah pohon pada kelas diameter $\geq 50 \mathrm{~cm}$ yang berjumlah 18 pohon/ ha (32 pohon/2,16 ha).

Menurut Keputusan Menteri Kehutanan No.88/Kpts-11/2003 tentang kriteria potensi hutan alam pada hutan produksi yang dapat dilakukan pemanfaatan hutan secara lestari menyebutkan bahwa potensi hutan minimal sebelum penebangan untuk rayon Kalimantan pada kelas diameter $\geq 50$ cm sebanyak 15 pohon/ha.

\section{KESIMPULAN}

1. Potensi terbesar dari jenis tengkawang yang ada di kebun masyarakat Dusun Tem’bak, Desa Gurung Mali, Kecamatan Tempunak, Kabupaten Sintang, Kalimantan Barat adalah dari jenis S.macrophylla dan S. stenoptera.

2. Jenis S. stenoptera di lembah memiliki potensi luas bidang dasar dan volume kayu tertinggi di bandingkan dua jenis lainnya.

3. Potensi tegakan tengkawang di desa tersebut masih tinggi dan dapat dikelola secara lestari.

4. Perlu terus untuk menyisihkan buah tengkawang dalam rangka regenerasi dan peningkatan potensi guna mendukung pengelolaan secara berkelanjutan.

5. Perlakuan silvikultur perlu dilakukan untuk peningkatan produktif tas tegakan (diameter dan tinggi), khususnya untuk tingkat semai dan pancang.

\section{DAFTAR PUSTAKA}

Fajri, M., Fernandes A., Suprianto A., Budiono M., (2012). Studi Level Pemanenan Buah Tengkawang Yang Lestari. Kementerian Kehutanan, Badan Litbang Kehutanan, Balai Besar Penelitian Dipterokarpa. Samarinda. 
Fajri, M. (2014). Analisis Vegetasi Dan Asosiasi Jenis Pada Habitat Shorea Macrophylla Di Hutan Tane’ Olen Desa Setulang, Kabupaten Malinau, Kalimantan Timur. Seminar Nasional Mapeki XVI Di Balikpapan. Mapeki Indonesia. Bogor.

Hardiyanto, E. B. (2008). Petunjuk Analisis Statistik Menggunakan SAS. Sekolah Pasca Sarjana UGM. Yogyakarta.

Heriyanto, M. N. \& Mindawati N. (2008). Konservasi Jenis Tengkawang (Shorea spp.) Pada Kelompok Hutan Sungai Jelai-Sungai DelangSungai Seruyan Hulu di Provinsi Kalimantan Barat. Info Hutan, 5 (3), 281 - 287.

ITTO Program PD 586/10 Rev.1 (F). (2011). Potensi Tengkawang di Lahan Masyarakat Lokal Kalimantan Barat. Brief Info, 4.

Keputusan Menteri Kehutanan No.88/Kpts-11/2003. (2003). Kriteria Potensi Hutan Alam Pada Hutan Produksi Yang Dapat Dilakukan Pemanfaatan Hutan Secara Lestari. Menteri Kehutanan Republik Indonesia. Jakarta.

Mukrimin, (2011). Analisis Potensi Tegakan Hutan Produksi di Kecamatan Parangloe, Kabupaten Gowa. Jurnal Hutan dan Masyarakat, 6 (1), $67-72$.

Muhdi. (2004). Pengaruh Elevasi Terhadap Pertumbuhan dan Kualitas Kayu. USU Digital Library. Medan.

Newman, M. F., Burgess P. F., \& Whitmore T. C. (1999). Pedoman Identifikasi Pohon-pohon Dipterocarpaceae. Prosea Indonesia. Bogor.
Peta Kalbar. (n.d.). Diakses pada 12 Mei 2015, dari http://4.bp.blogspot.com/-s1600/17peta_ kalbar.gif

Peta Sintang. (n.d.). Diakses pada 12 Mei 2015, http://2. bp.blogspot.com/s1600/SintangAllNew.jpg

Purwaningsih. (2006). Analisis Vegetasi Hutan Pada Beberapa Ketinggian Tempat di Bukit Wawauwai, Pulau Wawonii, Sulawesi Tenggara. Biodiversitas 7 (1), 49 - 53.

Riko, A. Lumangkun \& Wardenaar E. (2013). Nilai Manfaat Tengkawang (Shorea spp.) Bagi Masyarakat Di Kecamatan Embaloh Hilir Kabupaten Kapuas Hulu Kalimantan Barat. Jurnal Hutan Lestari 1 (2), 83 - 91.

Sidiyasa, K., Zakaria \& Iwan R. (2006). Hutan Desa Setulang dan Sengayan Malinau, Kalimantan Timur (Potensi dan Identifikasi Langkah-langkah Perlindungan dalam Rangka Pengelolaannya Secara Lestari). CIFOR. Bogor.

Subiandono, E., Bismark M., \& Heriyanto N. M. (2010). Potensi Jenis Dipterocarpaceae di Hutan Produksi Cagar Biosfer Pulau Siberut, Sumatera Barat. Buletin Plasma Nutfah, 16 (1), $64-71$.

Wahyudi, A., Saridan, A., \& Rombe R. (2010). Sebaran dan Asosiasi Jenis Pohon Penghasil Tengkawang (Shorea spp.) di Kalimantan Barat. Kementerian Kehutanan, Badan Litbang Kehutanan, Balai Besar Penelitian Dipterokarpa. Samarinda. 